\title{
ANATOMICAL VARIATIONS IN THE ORIGIN OF SUPERIOR THYROID ARTERY AND ITS RELATION WITH EXTERNAL LARYNGEAL NERVE AND THEIR CLINICAL IMPORTANCE- A CADAVERIC STUDY
}

Manjappa T, ${ }^{1}$ Ruku Pandit ${ }^{1}$

\section{ABSTRACT}

\section{INTRODUCTION}

The major arterial supply of thyroid gland is from superior and inferior thyroid arteries. The superior thyroid artery (STA) usually arises from the external carotid artery. The external laryngeal nerve runs in close proximity to the origin of the superior thyroid artery later leaves the artery by turning medially above or below the upper pole of the thyroid gland.

\section{MATERIAL AND METHODS}

A descriptive study was undertaken on 20 embalmed cadavers. The anterior triangle of neck was dissected bilaterally. The site of origin of STA level of origin in relation to the upper border of lamina of thyroid cartilage and relation of the STA with external laryngeal nerve were observed and noted.

\section{RESULTS}

The STA arises from the external carotid artery in $27.5 \%$, common carotid artery in $62.5 \%$, common carotid bifurcation in $5 \%$ and arises by a common trunk with lingual artery at common carotid bifurcation in $5 \%$. The distance from the upper pole to the point where external laryngeal nerve turns medially is more than $10 \mathrm{~mm}$ in $50 \%$, less than $10 \mathrm{~mm}$ in $25 \%$ and 10 $\mathrm{mm}$ in $25 \%$.

\section{CONCLUSION}

The variations in the pattern of origin of the superior thyroid artery and its relation to external laryngeal nerve is a very common phenomenon. The head and neck surgeons must be aware of all possible variations to avoid postoperative complications and legal issues.

\section{KEYWORDS}

External carotid artery, External laryngeal nerve, Superior thyroid artery.

1. Department of Anatomy, College of Medical Sciences, Bharatpur, Nepal

DOI: http//doi.org/10.3126/jucms.v9i01.37964

For Correspondence

Dr. Manjappa T

Department of Anatomy,

College of Medical Sciences,

Bharatpur, Nepal

Email:manjappa7406@gmail.com 


\section{INTRODUCTION}

The superior thyroid artery (STA) arises from the front of the external carotid artery (ECA) just below the level of greater cornu of hyoid, dividing into terminal branches at the apex of the thyroid lobe but may arise from the common carotid artery (CCA). Medial are the constrictor pharynges inferior and external laryngeal nerve; the nerve is often posteromedial. ${ }^{1}$ The lingual artery often arises with the facial or, less often with the STA. Past studies have reported the incidence of origin of STA from common carotid artery in $5-45 \%$ cases. ${ }^{2}$ Because of close association of STA with external laryngeal nerve (ELN), during thyroid surgery, STA should be ligated close to the gland to avoid injury to ELN. Variations in the origin and distribution pattern of STA are of great importance for head and neck surgeries because of its vital relationship to the external branch of superior laryngeal nerve. ${ }^{3,4}$

The external branch of the superior laryngeal nerve (EBSLN), which supplies the cricothyroid muscle, runs parallel to STA and later crossing the artery from lateral to medial either above or below the upper pole of the thyroid gland. ${ }^{5,6}$ The cricothyroid muscle is a tensor of vocal cords. This muscle tenses the vocal folds to produce high frequency sounds during phonation, protect the airways against respiration during swallowing and optimize breathing. ., $^{2}$

In case of thyroidectomy, STA must be ligated and is highly essential to ensure proper hemostasis. ${ }^{8}$ Because of its intimate relationship with STA, EBSLN is at risk when the artery being ligated. ${ }^{3,4,9}$ The injury to ELN causes paralysis of cricothyroid muscle. Thus EBSLN injury may alter the ability to produce acute sounds and lead to dysphagia, especially with liquids. ${ }^{4}$ Clinical symptoms may present as weakness, tightness, increased effort to speak, increased throat clearing and vocal fatigue. $^{10,11}$ The severity may vary depending on the voice demands of the person and it is felt that singer and professional voice users such as lawyers, teachers and broadcasters are more significantly affected by the subtle changes related to its injury. ${ }^{11,12}$ Even for non-professionals, the perception of an abnormal voice impairs the quality of voice and decreases the general health in many ways and affected patients may be unable to shout for help. ${ }^{10}$

The incidence of EBSLN injury in patients undergoing thyroidectomy is reported to be up to $58 \%{ }^{8,10,13}$ One of the earliest reported case goes back to 1935 when the famous opera singer Amelita Galli-Curci suffered from damage to the EBSLN after thyroid surgery. This nerve has since become known as the "nerve of Galli-Curci". ${ }^{11,12}$ Identification of arterial variations related to the thyroid gland is of immense importance in formulating planned surgical approaches to the thyroid glands in alerting the surgeons to avert inadvertent injuries to the vital anatomical structures in this area. Additionally, a detailed knowledge of these explicit arterial variations is extremely useful while carrying out procedures like carotid angiographies, neck dissections and thyroid resections. ${ }^{14}$

\section{MATERIAL AND METHODS}

A descriptive cross sectional institutional based observation study was conducted on 40 embalmed human cadavers. The study samples were cadavers used for teaching purpose for medical and dental students in College of Medical Sciences, Bharatpur, Nepal. The dissection of anterior triangle of neck is conducted bilaterally according to "Cunningham's Manual of practical anatomy, fifteenth edition, to expose the common carotid artery and its bifurcation, external carotid artery and origin of STA, external laryngeal nerve and its relation with STA, thyroid gland and thyroid cartilage.

In this study, site of origin of STA, level of origin of STA in relation to the upper border of thyroid lamina, distance from the upper pole of thyroid lobe to the point where the external laryngeal nerve turns medially from STA, distance between the point of origin of STA to the common carotid bifurcation is noted. The sliding calipers is used to measure the distance.

The study was conducted after obtaining the clearance from the Institutional Ethical review committee of College of Medical Sciences, Bharatpur, Nepal.

\section{RESULTS}

The STA arises from external carotid artery in $27.5 \%$ (30\% in right side and $25 \%$ in left side), from common carotid artery in $62.5 \%$ ( $55 \%$ in right side and $70 \%$ in left side), from common carotid artery bifurcation in 5\% (5\% in right side and 5\% in left side) and by a common trunk with lingual artery in 5\% (10\% only right side). (Table 1)

Origin of STA is above the upper border of thyroid lamina in $25 \%$ (35\% in right side and $15 \%$ in left side), at the level of the upper border of thyroid lamina in $22.5 \%$ (20\% in right side and $25 \%$ in left side) and below the level of the upper border of thyroid lamina in $52.5 \%$ (45\% in right side and $60 \%$ in left side). (Table 2)

Distance from the upper pole of thyroid lobe to the point where external laryngeal nerve turns medially from STA is more than $10 \mathrm{~mm}$ in $50 \%$ (20\% in right side and $80 \%$ in left side), less than $10 \mathrm{~mm}$ in $25 \%$ (35\% in right side and $15 \%$ in left side) and $10 \mathrm{~mm}$ in $25 \%$ ( $45 \%$ in right side and $5 \%$ in left side). (Table 3 )

Distance from the point of origin of the STA to the common carotid artery bifurcation is more than $10 \mathrm{~mm}$ in $12.5 \%(10 \%$ in right side and $15 \%$ in left side), less than $10 \mathrm{~mm}$ in $82.5 \%$ ( $80 \%$ in right side and $85 \%$ in left side) and 0 distance means origin at the bifurcation is 5\% (5\% in right side and 5\% in left side). (Table 4) 
Table1. Site of origin of superior thyroid artery

\begin{tabular}{lccc}
\hline Site of origin & Right side (n=20) & Left side $(\mathrm{n}=\mathbf{2 0})$ & Total $(\mathrm{n}=\mathbf{4 0})$ \\
\hline External carotid artery (ECA) & $06(30 \%)$ & $05(25 \%)$ & $11(27.5 \%)$ \\
\hline Common carotid artery (CCA & $11(55 \%)$ & $14(70 \%)$ & $25(62.5 \%)$ \\
\hline $\begin{array}{l}\text { Common carotid artery } \\
\text { bifurcation (CCAB) }\end{array}$ & $01(5 \%)$ & $01(5 \%)$ & $02(5 \%)$ \\
$\begin{array}{l}\text { By CT with 1 ingual artery at } \\
\text { CCAB }\end{array}$ & $02(10 \%)$ & $---1----$ & $02(5 \%)$ \\
\hline Total & 20 & 20 & 40 \\
\hline
\end{tabular}

Table 2. Level of origin of the STA in relation to the upper border of thyroid lamina

\begin{tabular}{lccc}
\hline Level of origin & $\begin{array}{c}\text { Right side } \\
(\mathrm{n}=20)\end{array}$ & $\begin{array}{c}\text { Left side } \\
(\mathrm{n}=20)\end{array}$ & Total $(\mathrm{n}=40)$ \\
\hline $\begin{array}{l}\text { Above the upper border of thyroid } \\
\text { lamina }\end{array}$ & $07(35 \%)$ & $03(15 \%)$ & $10(25 \%)$ \\
$\begin{array}{l}\text { At the upper border of thyroid lamina } \\
\begin{array}{l}\text { Below the upper border of thyroid } \\
\text { lamina }\end{array}\end{array}$ & $04(20 \%)$ & $05(25 \%)$ & $09(22.5 \%)$ \\
\hline
\end{tabular}

Table 3. Distance from the upper pole of thyroid gland to the point where external laryngeal nerve turns medially from STA

\begin{tabular}{lccc}
\hline Distance & Right side (n=20) & Left side (n=20) & Total $(\mathrm{n}=40)$ \\
\hline $10 \mathrm{~mm}$ & $09(45 \%)$ & $01(5 \%)$ & $10(25 \%)$ \\
More than 10 mm (average 12 mm) & $07(35 \%)$ & $03(15)$ & $10(25 \%)$ \\
Less than 10 mm (average 7 mm) & $04(20 \%)$ & $16(80 \%)$ & $20(50 \%)$ \\
\hline
\end{tabular}

Table 4. Distance between the point of origin of STA and common carotid artery bifurcation

\begin{tabular}{lccc}
\hline Distance & Right side $(\mathrm{n}=20)$ & Left side $(\mathrm{n}=20)$ & Total $(\mathrm{n}=40)$ \\
\hline $0 \mathrm{~mm}$ (origin at CCAB) & $01(5 \%)$ & $01(5 \%)$ & $2(5 \%)$ \\
More than 10 mm (average 11 mm) & $03(15 \%)$ & $02(10 \%)$ & $05(12.5 \%)$ \\
Less than 10 mm (average 5 mm) & $16(80 \%)$ & $17(85 \%)$ & $33(82.5 \%)$
\end{tabular}

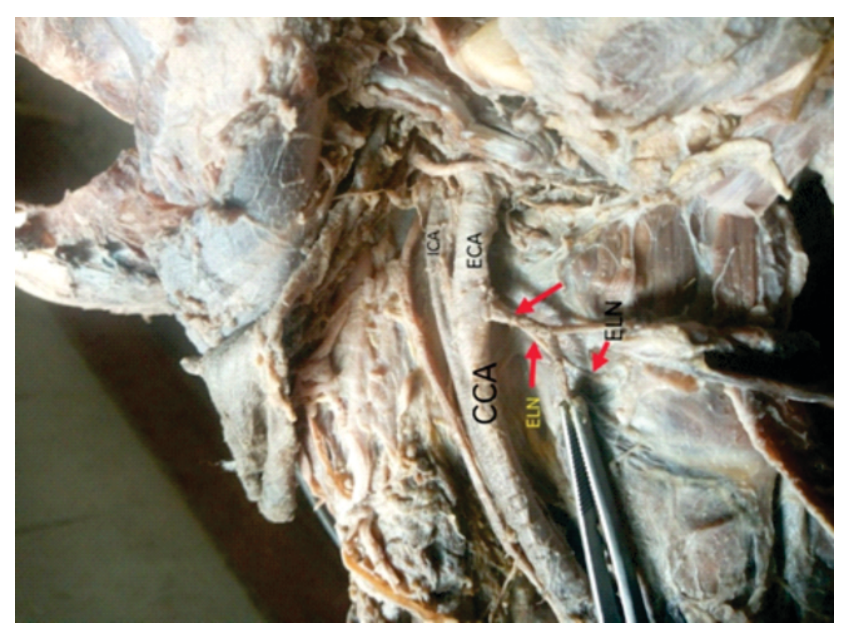

Figure 1. Showing the origin of STA from right CCA 0.2 $\mathrm{mm}$ below the $\mathrm{CCAB}$ and external laryngeal nerve is posterior at the origin of STA and turning medially away from STA at $10 \mathrm{~mm}$ above the apex of thyroid lobe

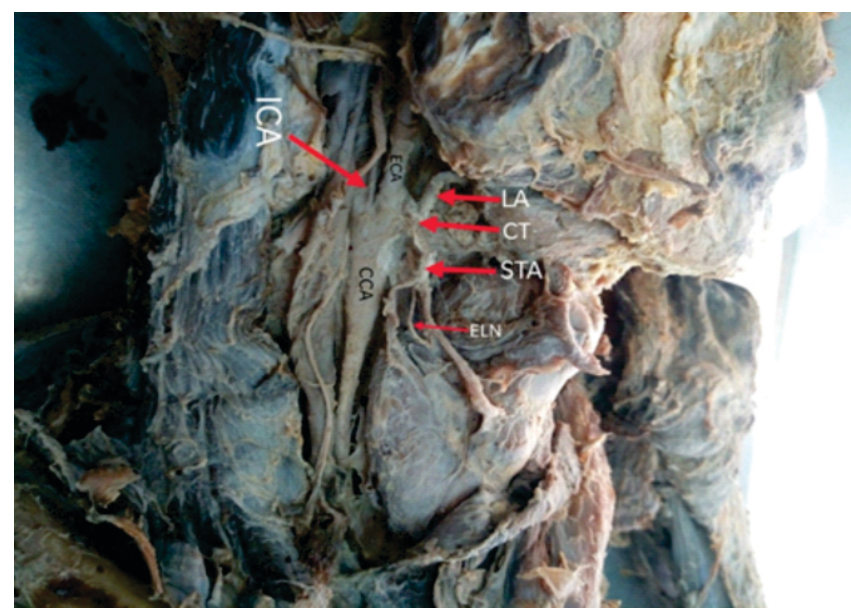

Figure 2. Showing the origin of STA by common trunk with lingual artery at right $\mathrm{CCAB}(0 \mathrm{~mm}$ from the $\mathrm{CCAB})$ and external laryngeal nerve is posterior at the origin of STA and turning medially away from STA at $0.5 \mathrm{~mm}$ above the apex of thyroid lobe

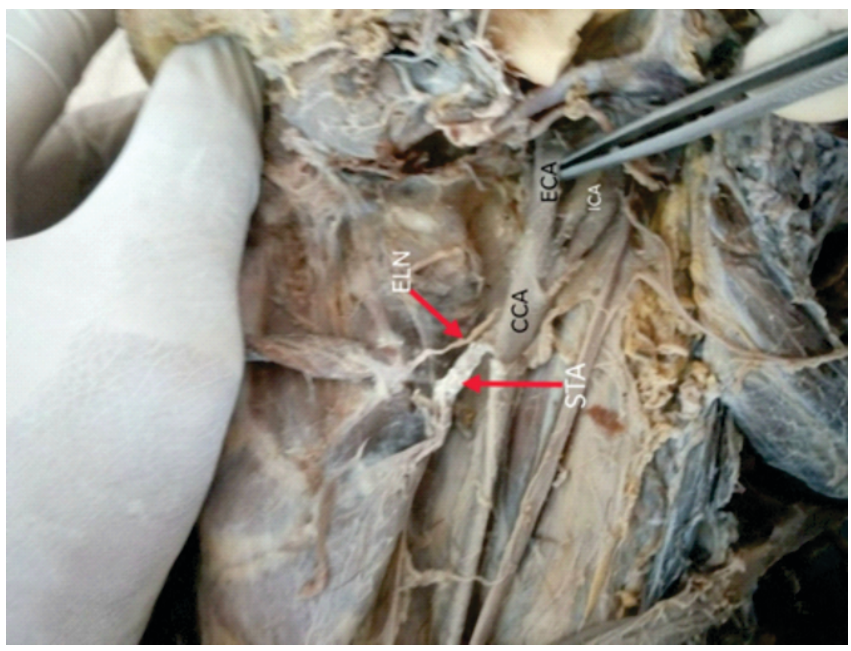

Figure 3. Showing the origin of STA from left CCA, $15 \mathrm{~mm}$ below the $\mathrm{CCAB}$ and external laryngeal nerve above the STA at the origin of STA and turning medially away from STA at $0.3 \mathrm{~mm}$ above the apex of thyroid lobe

\section{DISCUSSION}

The STA is considered to have a relatively constant origin from the anterior surface of the external carotid artery $(\mathrm{ECA})^{15,16}$ but many studies have reported wide variations in the origin of STA. The STA frequently arises from ECA just above the carotid bifurcation. It may also arise from the common carotid artery (CCA), from CCA bifurcation (CCAB), as a common trunk with lingual and facial branches from $\mathrm{ECA}^{17}$ but in present study arises as a common trunk with lingual artery. The origin of STA from ECA shows wide 
variations ranging from $20 \%$ in the study of Won $\mathrm{SY}^{18}$ to $88.33 \%$ in the study Ranjith Sreedharan ${ }^{19}$ and in present study it shows $27.5 \%$ which is very much near to the study of Ozgur et al. ${ }^{20}$ The origin of STA from CCA also shows much wide variations ranging from $1.5 \%$ in the study of Abhijeeth Joshi ${ }^{21}$ to $62.5 \%$ in the present study. The origin of STA from CCA bifurcation was a primary site of origin in the study done by Vazquez et $\mathrm{al}^{22}$ which accounts $49 \%$ and minimum incidence of $2.2 \%$ was reported by Ongeti $\mathrm{KW}^{23}$ but in the present study it is $5 \%$. The origin of STA as common trunk with lingual artery at CCA bifurcation was not reported in any of the studies but in the present study it accounts to $5 \%$. The origin of STA as a thyrolingual trunk was reported $0.6 \%$ in the study of Vazquez et $\mathrm{al}^{22}$ and $2.5 \%$ in the study of Ozgur et al. ${ }^{20}$ The origin of STA as thyrolinguofacial trunk was also reported in the studies of Ozgur et al Vazquez et al and Onget KW as 6.5\%, $0.3 \%$ and $7 \%$ respectively.

Table 5 . Incidence of origin and mode of origin of superior thyroid artery

\begin{tabular}{|c|c|c|c|c|c|c|}
\hline Authors & ECA & CCA & CCAB & $\begin{array}{l}\text { By CT with } \\
\text { facial artery } \\
\text { and lingual } \\
\text { artery from } \\
\text { ECA }\end{array}$ & $\begin{array}{c}\text { By CT } \\
\text { with } \\
\text { lingual } \\
\text { artery } \\
\text { from ECA }\end{array}$ & $\begin{array}{l}\text { By CT } \\
\text { with } \\
\text { lingual } \\
\text { artery } \\
\text { from } \\
\text { CCAB }\end{array}$ \\
\hline Thakkapalli Anita et al & $59 \%$ & $21 \%$ & $19 \%$ & & & \\
\hline Lucev & $30 \%$ & $47.50 \%$ & $22.50 \%$ & & & \\
\hline Banna $\mathrm{M}$ et al & $68 \%$ & $10 \%$ & $22 \%$ & & & \\
\hline Abhijeeth Joshi & $66.67 \%$ & $1.5 \%$ & $31.81 \%$ & & & \\
\hline Ranjith Sreedharan & $88.33 \%$ & $3.33 \%$ & $8.33 \%$ & & & \\
\hline Won SY & $20 \%$ & $40 \%$ & $40 \%$ & & & \\
\hline Ozgur et al & $25 \%$ & $35 \%$ & $40 \%$ & $6.5 \%$ & $2.5 \%$ & \\
\hline Vazquez et al & $23 \%$ & $26 \%$ & $49 \%$ & $0.3 \%$ & $0.6 \%$ & \\
\hline MA Dessie & $44.2 \%$ & $26.7 \%$ & $27.9 \%$ & $2.3 \%$ & $2.3 \%$ & \\
\hline Present study & $27.5 \%$ & $62.5 \%$ & $5 \%$ & (-) & 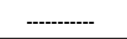 & $5 \%$ \\
\hline
\end{tabular}

In the current study, the origin of STA is above the level of the upper border of thyroid lamina in $25 \%$, at the level of upper border of thyroid lamina in $22.5 \%$ and below the level of upper border of thyroid lamina is $52.5 \%$. The level of origin of STA is above the upper border thyroid cartilage is $99.66 \%$ in the study of Ranjith Sreedhran, ${ }^{19} 51.2 \%$ in the study of MA Dessie $^{17}$ and $86.36 \%$ in the study of Joshi et al. ${ }^{24}$ The origin at level of upper border of thyroid cartilage is $44.7 \%$ in the study of MA Dessie, ${ }^{17} 13.64 \%$ in the study of Joshi et $\mathrm{al}^{24}$ and $1.66 \%$ in the study of Ranjith Sreedharn. ${ }^{19}$ The origin of below the level of thyroid cartilage is $1.6 \%$ in the study of Ranjith Sreedhran. ${ }^{19}$

In the present study, the distance from the upper pole of thyroid lobe to the point where external laryngeal nerve turns medially from STA is $10 \mathrm{~mm}$ in $25 \%$, more than $10 \mathrm{~mm}$ (average $12 \mathrm{~mm}$ ) in $50 \%$ and less than $10 \mathrm{~mm}$ in $25 \%$ (average $7 \mathrm{~mm}$ ). The study conducted by various authors shows that, the distance of $1 \mathrm{~cm}$ or more than $1 \mathrm{~cm}$ in $75 \%$ (Magoma et al), $72.73 \%$ (Joshi et al) ${ }^{24} 60 \%$ (Estrela et al) ${ }^{4}{ }^{4} 57 \%$ (MADessie). ${ }^{17}$ In the current study, the distance between the point of origin of
STA and common carotid artery bifurcation is more than 10 $\mathrm{mm}$ (average $11 \mathrm{~mm}$ ) in 12.5\%, and less than $10 \mathrm{~mm}$ (average in $87.5 \%$, at the bifurcation means $0 \mathrm{~mm}$ in $5 \%$. The study conducted by MA Dessie and Vazquez shows the distance of $0.2 \mathrm{~cm}$ to $3.5 \mathrm{~cm}$ and $0.1 \mathrm{~cm}$ to $2.1 \mathrm{~cm}$ respectively. ${ }^{17,22}$

\section{CONCLUSION}

A profound knowledge of the anatomical variations of the STA such as origin, course, and relation to external laryngeal nerve is of paramount importance to the head and neck surgeons as wide range of variations is a common phenomenon. The awareness of anatomic variations may also warn surgeons during external carotid artery ligation in uncontrollable bleeding during thyroid and radical neck surgeries

\section{REFERENCES}

1 Williams-Grey's anatomy, $38^{\text {th }}$ edition. $1995 ; 1516$.

2 Smith SD, Bentson RS. A rare origin of superior thyroid artery. Act Anat.1978;101:91-3.

3 Dhindsa GS, Sodhi S. Variations in the origin of superior thyroid artery. Journal of Evolution of Medical and Dental sciences. 2014;3(22):5969-72.

4 Estrela F, Leao HZ, Jotz GP. Anatomical relation between the external branch of the superior laryngeal nerve and the thyroid gland. Braz J Otolaryngol. 2011;77(2):249-58.

5 Magoma G, Saidi H, Kaisha W. Relation of the external laryngeal nerve to superior thyroid artery in African Population. Anatomical Journal of Africa. 2012;1(1):27-9.

6 Sarkar S, Kundu B, Dey S, Saha PK, Meur R, Sadhu A. Variations in the arterial supply of the thyroid gland in an Indian male cadevar. Indian Journal of Basic and Applied Medical Reasearch. 2014;3(3):256-259.

7 Bathello JB, Neto JC, Anjos GSD, Carvalho DMD, Melo YDSD, Junior EGDS, et al. Relation between the external branch of superior laryngeal nerve and superior thyroid artery: a study in 101 nerves. Rev Col Bras Cir. 2009;36(3):187-92.

8 Menon RR, Murali S, Nair CG, Babu MJC, Jacob P. Correlation between the Cernea classification of external branch of superior laryngeal nerve in relation to the ultrasound based volume of thyroid gland. Indian J Endocrinol Metabolism. 2017;21(6):845-7.

9 Paul M, Ghosh R, Samanta C, Banerjee M, Pradhan S, Kar M, et al. Variations of the superior thyroid artery and Internal jugular vein. Indian Journal of Basic and Applied Medical Research. 2015;5(1):25-9.

10 Potenza AS, Filho VJFA, Cernea CR. Injury to the external laryngeal nerve in thyroid surgery. Gland Surg. 2017;6(5):55262. 
11 Friedman M, Losavio P, Ibrahim H. Superior laryngeal nerve identification and preservation in thyroidectomy. Arch Otolaryngol Head and Neck Surg. 2002;128:296-303.

12 Patnaik U, Nilakantan A. Identification of external branch of the superior laryngeal nerve in thyroid surgery: is it always possible? Thyroid disorders Ther.2013;2(2).

13 Cha YH, Moon S-Y, Jehoon O, Tansatit T, Yang H-M. Anatomy of the external branch of the superior laryngeal nerve in Asian population. Sci Rep. 2017 Nov;7(1):14952.

14 Yilmaz E, Celik HH, Durgun B, Atasever A, Igli S. Arteria thyroidea ima arising from brachiocephalic trunk with bilateral absence of inferior thyroid arteries. A case report. Surg Radiol Anat. 1993;15(3):197-9.

15 Moore KL, II AFD. Clinically Oriented Anatomy, $5^{\text {th }}$ Edition 2006.

16 Marieb EN, Wilhelm PB, Mallett J. Human anatomy sixth edition media update. United States of America: Pearson Education; 2012.

17 Dessie MA. Variations of the origin of superior thyroid artery and its relationship with external branch of superior laryngeal nerve. PLoS ONE. 2018;13(5):e0197075.

18 Won SY. Anatomical considerations of the superior thyroid artery: its origin, variations and position relative hyoid bone and thyroid cartilage. Anat Cell Bio. 2016;49(2):138-42.

19 Ranjith Sreedharan, Lalu Krishna, Ashwija Shetty. Origin of superior thyroid artery: under the surgeon's knife. J Vasc Bras.2018;17(4):290-295.

20 Ozgur Z, Govsa F, Celik S, Ozgur T. Clinically relevant variations of superior thyroid artery: an anatomical guide for surgical neck dissection. Surg Radiol Anat. 2009;31(3):151-9.

21 Abhijeet Joshi, Sumit Gupta, V H Viniya. Anatomical variations in the origin of superior thyroid artery and its relation with external laryngeal nerve. National Journal of Medical Research. 2014;4(2):138-141.

22 Vázquez T, Cobiella R, Maranillo E, Valderrama FJ, McHanwell S, Parkin I, Sañudo JR. Anatomical variations of the superior thyroid and superior laryngeal arteries. Head Neck. 2009 Aug;31(8):1078-85.

23 Ongeti KW, Ogengo JA. Variant origin of the superior thyroid artery in a Kenyan population. Clinical Anatomy. 2012;25:198202.

24 Joshi A, Gupta S, Vinay VH. Anatomical variation in the origin of superior thyroid artery and its relation with external laryngeal nerve. National Journal of Medical Research. 2014:4(2):13841. 